\title{
A TRANSPOSIÇÃO DIDÁTICA E O CONCEITO DE FUNÇÃO
}

\author{
Edson Alkimim ${ }^{1}$ e Maria Auxiliadora Vilela Paiva ${ }^{2}$
}

\author{
Programa de Pós-graduação em Educação em Ciências e Matemática \\ Instituto Federal do Espírito Santo - Campus Vitória \\ Avenida Vitória, 1729 - Bairro Jucutuquara 29040-780 - Vitória - ES
}

Tel.: (27) 3331-2110 Fax: (27) 3331-2222

\begin{abstract}
RESUMO
O objetivo deste trabalho foi estudar a transposição didática do conceito de função em sala de aula de uma escola pública de Ensino Médio do Estado do Espírito Santo. A pesquisa, de natureza qualitativa com uma metodologia descritiva de estudo de caso, foca a introdução do conceito de função, utilizando para tal, observações de sala de aula, entrevistas com os professores e análise do livro didático adotado. Neste artigo, parte da revisão bibliográfica da pesquisa, procuramos entender os mecanismos de transposição didática baseados em referenciais teóricos que reconhecem a escola como um espaço caracterizado pela produção e transformação de conhecimentos e não simplesmente repetidora de conhecimentos científicos, no qual o ensino-aprendizagem da matemática se dá dentro de uma visão crítica. Podemos afirmar após esta pesquisa que o professor, ao resgatar o enfoque histórico e modelar situações do cotidiano no estudo do conceito de funções para desenvolver o pensamento variacional, poderá propiciar a construção deste conceito e sua utilização crítica.
\end{abstract}

Palavras-chaves: transposição didática, conceito de função, ensino-aprendizagem.

\begin{abstract}
The objective of this study was to study the didactic transposition of the concept of function in the classroom of a public secondary school in the State of Espírito Santo. The research was qualitative descriptive methodology with a case study, focuses on the introduction of the concept of function, using for that purpose, classroom observations, interviews with teachers and analysis of textbooks adopted. In this article, part of the literature review of research, we understand, in which the teaching-learning mechanisms didactic transposition based on theoretical frameworks that recognize the school as a space characterized by the production and processing of knowledge and not simply repeater scientific knowledge mathematics occurs within a critical view. We can say after this research that the teacher, to rescue the historical approach and modeling real-world situations in the study of the concept of functions to develop the variational thought, can foster the construction of this concept and its critical use .
\end{abstract}

Keywords: didactic transposition, concepts of function; teaching and learning process.

\footnotetext{
1 Professor de Matemática, Mestre em Educação em Ciências e Matemática. Secretaria Municipal de Educação da Serra - ES. E-mail: ealkimim@gmail.com

2 Professora de Matemática, Doutora em Matemática. Docente do Programa de Mestrado em Educação em Ciências e Matemática do Instituto Federal do Espírito Santo. E-mail: vilelapaiva@gmail.com
} 


\section{INTRODUÇÃO}

Os saberes de domínio escolar têm, em geral, como parâmetro necessário os saberes científicos aceitos pela comunidade científica de uma determinada área de conhecimento, a partir do qual será feita a transposição didática de conceitos e hipóteses para o contexto de sala de aula. Esse é um tema que tem sido pesquisado por vários autores da área da educação e, em particular, do ensino de ciências e matemática. No campo da didática da matemática, Chevallard (1991) apud Leite (2004, p. 45) afirma que

Um conteúdo de saber que tenha sido definido como saber a ensinar, sofre, a partir de então, um conjunto de transformações adaptativas que irão torná-lo apto a ocupar um lugar entre os objetos de ensino. 0 'trabalho' que faz de um objeto de saber a ensinar, um objeto de ensino, é chamado de transposição didática.

Complementa esta definição ao dizer que "Os processos transpositivos - didáticos e, mais genericamente, institucionais - são, imagina-se, a mola essencial da vida dos saberes, de sua disseminação e de sua funcionalidade adequada" (CHEVALLARD (1991) apud MARANDINO, 2004, p. 95).

Podemos inferir que a Transposição Didática (TD) está diretamente ligada ao processo de ensinar e aprender; daí a importância dada à transposição didática por Chevallard e demais autores que tratam desta problemática. Outra questão apontada é que o processo de produção de conhecimentos pretendida pela transformação de saberes científicos em saberes de domínio escolar é "adaptativo". Portanto, deve-se construir uma concepção de transposição didática adaptada às realidades de cada escola, considerando as especificidades locais e adequadas ao processo de socialização dos alunos, numa concepção de educação matemática crítica.

A nossa preocupação na pesquisa em geral é sobre a forma com a qual o conceito de função vem sendo tratado pelos professores de matemática em sala de aula. A pesquisa aponta que ao resgatar o enfoque histórico e modelar situações do cotidiano no estudo do conceito de funções para desenvolver o pensamento variacional, o professor poderá propiciar a construção deste conceito e a utilização crítica no cotidiano. É necessário, no entanto, que o professor entenda o processo de transposição didática para conduzir seus alunos na construção de modelos, possibilitando-lhes a investigação à cerca do objeto matemático de estudo, entendendo como as grandezas nas diversas situações variam. 
Discutimos neste trabalho os processos de construção do conceito de função a partir da transposição didática, buscando aprofundar e discutir suas aplicações, problematizando o seu uso para o estudo de função. Em seguida, pesquisamos a formação histórica do conceito de função, refazendo a trajetória da produção do saber científico deste conceito. Por fim apresentamos as orientações dos PCNs para promover a transposição didática no estudo do conceito de função.

\section{A TRANSPOSIÇÃO DIDÁTICA: DO SABER CIENTÍFICO AO SABER ENSINADO}

Para transmitir um conhecimento se faz necessária sua modificação deixando-o mais acessível para sua apropriação. Esta modificação, que vem sendo alvo de estudiosos, é chamada de transposição didática. A transposição ocorre quando o conteúdo já transposto pelo currículo proposto é selecionado pelo professor de acordo com o que considera relevante, de forma a constituir as competências na sua proposta pedagógica. Desse modo alguns aspectos ou temas são mais enfatizados, reforçados ou diminuídos, determinando uma forma de organizar e apresentar os conteúdos, por meio de textos, gráficos, e outras representações pertinentes.

A transposição didática de um determinado saber depende diretamente das influências externas que ele sofre na sua trajetória, contribuindo para uma redefinição de conceitos e para a reformulação de sua apresentação como saber a ser ensinado. Leite (2004) afirma que esta influência é exercida por uma interface entre o saber e os especialistas de educação, as políticas públicas, os autores de livros, professores e comunidades, entre outros, recebendo o nome de noosfera, segundo descrição de Chevallard, evidenciando uma inserção da representação do sistema didático na sociedade. Desta maneira,

\footnotetext{
No entorno social, estariam incluídos os matemáticos, as famílias dos estudantes, as instâncias políticas de decisão; no sistema didático stricto sensu, atuam professores e alunos; a noosfera seria encarregada de realizar a interface entre a sociedade e as esferas de produção dos saberes, dela participando, em posições diferenciadas. (LEITE 2004, p. 60),
}

A influência sofrida pela noosfera resulta não só na escolha de conteúdos, como também na definição de objetivos, métodos e valores que conduzem o sistema de ensino. Ainda conforme Leite(2004), a noosfera seria responsável, no plano do saber, por viabilizar a compatibilidade entre o sistema didático e o contexto social e seu entorno. 
Para discutir esse processo, Chevallard propõe o seguinte modelo de interpretação: tal compatibilidade dependeria da sustentação do saber ensinado em um ponto mais ou menos equidistante entre o saber sábio e o saber "banalizado", acessível às famílias dos estudantes, sem a mediação escolar. Quando o saber ensinado se afasta demais do saber sábio, ocorre o que o autor chama de "envelhecimento biológico", passando a ter a legitimidade questionada pelo entorno social devido à sua obsolência.( Leite 2004, p. 6061),

Portanto, por essas reflexões, podemos inferir que a noosfera é uma zona de conflito, tendo em vista que as transformações que tramitam no processo de transposição didática respondem às contradições de uma demanda social.

O conhecimento, por sua vez, surge dentro de um campo científico e, para que possa ser ensinado, precisa passar por transformações que o vão moldando, tornando-o acessível aos alunos. Conforme Chevallard (1991) apud Dominguini (2008), o conhecimento passa por, pelo menos, três tipos distintos de transformações: o conhecimento como saber científico, saber a ensinar e saber ensinado.

O saber científico é aquele produzido por meio de um conjunto de regras específicas de produção de conhecimentos, as quais consistem em juntar evidências reais baseadas na verificação e observação sistemática, controladas e analisadas com o uso da lógica da ciência. Trata-se de um conhecimento apurado, advindo de uma atividade criteriosa, que segue um método de investigação, onde, por meio da observação da experiência, coletam-se dados a fim de se montar uma hipótese para explicar um fenômeno. 0 saber científico não pode ser ensinado como é em seu estado de criação, ou seja, em linguagem científica, tem de ser modificado para uma linguagem que seja acessível a todos. Ele deve passar por algumas transformações, para que possa ser elaborado de forma didática e constituir-se em saber a ensinar.

O saber a ensinar é o saber científico selecionado para ser apresentado em sala de aula, em linguagens orais e escritas, linguagens estas condicionadas à noosfera e ajustadas às condições em que se ensina e se aprende na escola. Ele se materializa na forma de currículo, livros didáticos, programas e materiais institucionais como cartilhas, softwares e outros materiais de apoio ao professor. Buscando compreender esse processo, Almeida (2007) apud Dominguini (2008, p. 12) afirma que: 
A transposição do conhecimento científico para o conhecimento escolar se dá primeiro com a definição da parte que será prioridade absorver. Depois, faz-se um apanhado da totalidade do conteúdo científico a fim de mostrar a sua amplitude. Essa visão mais ampla precisa ser, no mínimo, projetada para que o aluno perceba que o horizonte é bem mais distante, mas que será, aos poucos, apropriado por ele.

Entendemos que a forma pelo qual o saber a ensinar é materializado nos materiais de apoio ao professor é uma das transformações da noosfera e que ao ensinar de forma crítica, nosso objetivo não é somente a definição e sim o conceito mais amplo com suas ligações com as questões socioculturais. Dái a importância de uma nova transformação que passa pelo fazer em sala de aula e assim nos remete ao saber ensinado.

O saber ensinado é o resultado do planejamento da aula e do ato pedagógico. É o resultado da transformação do conteúdo definido, mediante adaptações e metodologias aplicadas pelo professor a um conteúdo específico de ensino, obtendo o resultado final: o conhecimento absorvido pelo aluno. Neste cenário o professor é visto como um dos principais personagens dessa transformação, uma vez que cabe a ele adequar o saber científico trazido nos livros para conhecimentos a serem discutidos e trabalhados em sala de aula, para melhor compreensão por parte dos alunos; mas numa visão da Matemática Critica o aluno e o contexto social em que vivem têm também um papel preponderante, já que o conhecimento é construído nas interações do terno: professoraluno-saber.

\section{CONCEITO DE FUNÇÃO: DO SABER CIENTÍFICO AO SABER ENSINADO}

O saber matemático, formalizado na forma que conhecemos e praticado em sala de aula, advém de um processo longo de construção que ocorreu concomitantemente à própria história da humanidade, sofrendo, ao longo dessa trajetória, transformações, deformações e distorções até chegar à forma pelo qual se apresenta em nossos dias. 0 conceito de função, historicamente, sempre se apresentou com certa relevância na formação matemática, ligando-se a situações que envolvem abstrações, interpretações e resolução de problemas relativos a diversos fenômenos estudados em várias áreas do conhecimento, destacando-se como uma ferramenta de relevância na produção científica e construção social. 
As principais etapas do desenvolvimento da noção de função são (0) A Pré-história que marcamos como a primeira ou marco zero delas, além das três outras existentes de acordo com a classificação devida à Youschkevitch (1981) apud Oliveira (1997, p.13-14):

(1) A Antiguidade: etapa no curso da qual o estudo dos diferentes casos de dependência entre duas quantidades ainda não isolou as noções gerais de quantidades variáveis e de funções.

(2) A Idade Média: Nesta etapa, estas noções são pela primeira vez, e de maneira precisa, expressas sob uma forma geométrica e mecânica, mas durante a qual, como na antiguidade, cada caso concreto de dependência entre duas quantidades é definida por uma descrição verbal ou por um gráfico, de preferência a uma fórmula.

(3) 0 período moderno: no curso do qual, a partir do fim do século XVI, e especialmente durante o século XVII, as expressões analíticas de funções começam a prevalecer; a classe das funções analíticas geralmente são expressas por meio de soma de séries infinitas, tomando-se logo a principal classe utilizada.

Na Pré-história, as pessoas viviam em pequenos grupos, alimentavam-se de caças e, para protegerem-se do tempo e dos inimigos, abrigavam-se em cavernas. Com o passar do tempo, os modos de vida foram se alterando e o homem deixa de ser apenas caçador e coletor, passando a ser agricultor, capturando e domesticando animais para tê-los como reserva de alimentos. Para controlar rebanhos e ter certeza de que nenhum animal havia fugido ou morto por predadores, usavam-se pedras fazendo uma relação unívoca entre o conjunto de pedras e a quantidade de animais do rebanho. A cada animal que se queria contar correspondia uma pedra. E, assim, relacionando objetos com outros objetos o homem começa a desenvolver a noção de função. Ponte (1990, p. 3), quando fala da origem da noção de função em seu trabalho, afirma que "é verdade que aspectos muito simples deste conceito podem ser encontrados em épocas anteriores (eles já estão presentes, por exemplo, na mais elementar operação de contagem)".

Na Antiguidade, entre os babilônios, em 2000 anos a.C., conforme relatado por Oliveira (1997), já existiam tabelas sexagesimais. Tais tabelas de correspondência revelavam um instinto funcional. Segundo a autora a estas tabelas podem ser atribuídas uma funcionalidade, pois uma função tem sido definida como uma tabela de correspondência. Ela afirma ainda, que entre os pitagóricos a ideia de função aparece no estudo de 
interdependência quantitativa de diferentes quantidades físicas, como, por exemplo, o comprimento e a altura da nota emitida por cordas da mesma espécie, pinçadas com tensões iguais. Este estudo revelou uma interdependência entre número, espaço e harmonia. Os egípcios, assim como os babilônios, também construíram tabelas para representar correspondência. Entre outros exemplos, Oliveira (1997, p. 15) afirma que

Apesar de tantos exemplos que indicam a presença das dependências funcionais, "não havia nenhuma ideia geral de funcionalidade na Antiguidade" (YOUSCHKEVITCH 1981, p.13). Portanto, o pensamento matemático da Antiguidade não criou nenhuma noção geral nem de quantidade variável nem de função.

Na Idade Média, conforme nos aponta Oliveira (1997), a primeira vez que a noção de função aparece numa forma "mais genérica" foi no século XII, quando alguns matemáticos estudaram fenômenos como o calor, luz, cor, densidade, distância, velocidade etc. Simultaneamente, a ideia de que as leis quantitativas da natureza eram leis do tipo funcional, amadurecia pouco a pouco na filosofia natural. A teoria das latitudes e longitudes das formas desenvolvidas por Nicole Oresme pode ser considerada como "a precursora da representação gráfica". Pode-se considerar que

\footnotetext{
Suas representações marcam um passo a frente, em direção ao conceito de função ou de variável dependente. Entretanto não se pode dizer que ele se utilizasse de funções. Com efeito, Oresme não se interessava pela forma na qual uma quantidade varia por razão do objeto que está dependente, mas antes pela configuração global da quantidade do objeto. Além disso suas representações eram totalmente imaginárias e qualitativas, e ele jamais utilizou medidas. Quem introduz o quantitativo nas suas representações é Galileu.
}

Foi então Galileu que, por meio de experimentações e instrumentos de medida, introduziu o quantitativo nas representações gráficas. Lidou de forma funcional com as causas e efeitos de suas experiências, necessidade essencial à concepção de variável dependente. 0 movimento (velocidade, aceleração e distância percorrida) foi o principal campo estudado por ele. Esta fase caracterizou o Período Moderno.

No entanto, segundo Oliveira (1997, p. 17) a generalização de quantidades expressadas por uma expressão geral surgiu em princípios do século XVI, época em que

os parâmetros algébricos se restringiam apenas a encontrar os valores desconhecidos numa dada equação com coeficiente numéricos específicos. A 
ideia de se estudar uma equação geral que representasse uma classe inteira de equações ainda não havia surgido, e esta ideia básica, de se fazer uma distinção clara entre parâmetros (valores conhecidos) e variáveis (valores desconhecidos) surgiu com François Vète.

Este autor comenta em sua obra que François Viète usava "consoantes" para representar parâmetros e "vogais" para representar variáveis, distinguindo por meio desta "Álgebra simbólica", quantidades dadas de quantidades desconhecidas, em substituição à "Algebra retórica" que era, até então, apresentada em linguagem corrente.

A importância desta notação que, pela primeira vez, tornou possível a colocação
por escrito sob uma forma simbólica das equações algébricas e de expressões
contendo quantidades desconhecidas e coeficientes arbitrários (um trabalho
que também nasceu com VIÈTE) poderia ser subestimada. Entretanto, o criador
da nova Álgebra não utiliza sua notável descoberta para “fazer avançar" o
conceito de função: pensar em termos de função não foi característica de seu
espírito. (YOUSCHKEVITCH (1981) apud OLIVEIRA, 1997, p. 17-18)

Esse método de introdução da representação das funções sob forma de equações foi estendido a outros ramos criando vínculos com a geometria, a mecânica, a física, etc. Segundo BOYER (1974, p. 297), “Leibniz não é responsável pela moderna notação de função, mas a ele que se deve a palavra "função", praticamente no mesmo sentido que é usada hoje". Ele usou o termo para descrever uma quantidade relacionada a uma curva. No entanto, para Ponte (1990, p. 3), "ainda apenas para designar, em termos mais gerais, a dependência duma curva de quantidades geométricas como a subtangentes $e$ subnominais. Introduz igualmente a terminologia de constantes, variáveis e parâmetros". Somente no século XVIII o termo "função" começa a aparecer como definição de um termo geral para diferentes segmentos ligados a uma curva.

Em Youschkevitch (1981), apud Oliveira (1997, p. 19-20) encontramos Bernoulli (16671748) - "Chamamos função de uma grandeza variável uma quantidade composta de qualquer maneira que seja desta grandeza variável e constante"; como também, Euler (1707-1783) - "Uma função de uma quantidade variável é uma expressão analítica composta de qualquer modo que seja, desta quantidade e números ou quantidade constante. Dirichlet (1805-1859) quebra a forma antes comportada da definição de função e fornece uma definição considerada ampla, mas que se aproximar da noção moderna de correspondência de conjuntos numéricos. Segundo ele, "Se uma variável y 
está relacionada com uma variável $x$ de tal modo que, sempre que é dado um valor numérico a $x$, existe uma regra segundo a qual um valor único de y fica determinado, então diz-se que y é função da variável independente x" (BOYER, 1974, p.405 ).

Na mesma época,

Hankel (1839-1873) - Diz-se que y é uma função de x se a cada valor de x de um certo intervalo, corresponde um valor bem definido de y sem que isto exija entretanto que y seja definido sobre todo intervalo pela mesma lei em função de $\mathrm{x}$, nem mesmo que y seja definido por uma expressão matemática explícita de x (YOUSCHKEVITCH, 1981, apud OLIVEIRA, 1997, p. 21).

Ao nos reportarmos às definições atribuídas à função no século $\mathrm{XX}$, encontramos em Oliveira (1997) algumas referências que mostram a definição de função como relação entre conjuntos.

Grupo Bourbaki - Sejam E e F dois conjuntos, distintos ou não. Uma relação entre uma variável x de E e uma variável y de F é dita uma relação funcional em $\mathrm{y}$, ou relação funcional de $\mathrm{E}$ em $\mathrm{F}$, se qualquer que seja $\mathrm{x} \in \mathrm{E}$, existe um e somente um elemento $y \in F$ que estela associado a x na relação considerada.

Dá-se o nome de função à operação que desta forma associa a todo elemento $\mathrm{x}$ $\in \mathrm{E}$ o elemento $\mathrm{y} \in \mathrm{F}$ que se encontra ligado a $\mathrm{x}$ na relação dada; diz-se que y é o valor da função para o elemento x, e que a função está determinada pela relação funcional considerada. Duas relações funcionais equivalentes determinam a mesma função (MENDES, 1994, apud OLIVEIRA, 1997, p. 21).

Uma função $\mathrm{f}$ de um conjunto $\mathrm{A}$ num conjunto $\mathrm{B}$, é uma regra de correspondência que associa a cada elemento de A no máximo um elemento de B (COTRET, 1988, apud OLIVEIRA, 1997, p. 22).

Função, como conjunto de pares ordenados, subconjunto do produto Cartesiano entre dois conjuntos é vista na definição: “Uma função $f$ de um conjunto $A$ em um conjunto $B$ é um subconjunto do produto cartesiano AxB que a cada a em $A$ associa um único elemento $b$ em B tal que $(a, b) \in f . "$ (SCHWARZ, 1995, apud OLIVEIRA, 1997, p. 22).

Esses estudos apontam que até a Idade Média, o conceito de função aparece a partir da conjunção de estudos "qualitativos" e "quantitativos" do movimento por meio de representações gráficas, após, começarem a considerar valores associados ao conceito de grandezas variáveis. A partir do século XIX, a definição de função aproxima-se da noção de correspondência de conjuntos numéricos, quando tal definição passa a ser 
apresentada como subconjunto de produto cartesiano AxB, dando maior importância, simplesmente, na correspondência entre elementos de dois conjuntos.

\section{AS ORIENTAÇÕES DOS PCN PARA PROMOVER A TRANSPOSIÇÃO DIDÁTICA NO ESTUDO DO CONCEITO DE FUNÇÃO}

Segundo os PCNs, é de extrema importância a compreensão do conceito de funções, para que o aluno possa interpretar e construir gráficos de comportamentos de diversos fenômenos do cotidiano, bem como de áreas específicas do conhecimento, como a geografia, física, química, economia etc. Nele é destacado que o seu ensino de forma isolada não permite abstrações, interpretações e resolução de problemas numa exploração do seu caráter integrador. De acordo com os PCN + Ensino Médio,

O estudo das funções permite ao aluno adquirir a linguagem algébrica como a linguagem das ciências, necessária para expressar a relação entre grandezas e modelar situações-problema, construindo modelos descritivos de fenômenos e permitindo várias conexões dentro e fora da própria matemática. Assim, a ênfase do estudo das diferentes funções deve estar no conceito de função e em suas propriedades em relação às operações, na interpretação de seus gráficos e nas aplicações dessas funções. (BRASIL, 2002, p. 121)

Sendo a transposição didática um conjunto de ações visando ao desenvolvimento de uma atividade didática que contribua para um aprendizado do aluno, o próprio PCNs pode ser visto pelo professor como mais uma ferramenta valiosa de contribuição para seu processo pedagógico. Pois, de acordo com os PCN + Ensino Médio Brasil (2002, p. 121),

Tradicionalmente o ensino de funções estabelece como pré-requisito o estudo dos números reais e de conjuntos e suas operações, para depois definir relações e a partir daí identificar as funções como particulares relações. Todo esse percurso é, então, abandonado assim que a definição de função é estabelecida, pois para a análise dos diferentes tipos de funções todo o estudo relativo a conjuntos e relações é desnecessário. Assim, o ensino pode ser iniciado diretamente pela noção de função para descrever situações de dependência entre duas grandezas, o que permite o estudo a partir de situações contextualizadas, descritas algébrica e graficamente. Toda a linguagem excessivamente formal que cerca esse tema deve ser relativizada e em parte 
deixada de lado, juntamente com os estudos sobre funções injetoras, sobrejetoras, compostas e modulares.

Podemos afirmar que os PCNs promovem claramente a transposição didática para o ensino do conceito de função, ressaltando a importância de se abandonar a linguagem formal de relações entre conjuntos e trabalhar situações problema que permitam ao aluno contextualizar situações de dependência entre grandezas. No que concerne ao estudo de funções, o ensino/aprendizagem da Matemática deve, portanto, propiciar ao aluno um nível de compreensão que lhe permita modelar problemas contextualizados e analisar situações problema de diversas áreas do conhecimento, estabelecendo relação de dependência entre grandezas.

\section{CONCLUSÃO}

0 processo de transposição didática está diretamente ligado ao processo de ensino/aprendizagem. Torna-se pois fundamental identificar os critérios a partir dos quais os professores possam operar no domínio da transposição didática, para que a produção de conhecimentos seja de forma adaptativa aos processos de socialização das pessoas. Assim, é importante entender os caminhos da transformação de saberes científicos em saberes a ensinar, e construir um ensino-aprendizagem de função que se adapte às realidades de cada escola numa concepção de Educação Matemática crítica.

O conceito de variação e de associação entre duas grandezas e suas relações funcionais, historicamente, só foi possível devido a um processo delicado e longo, que culminou com as definições do Grupo Bourbaki para funções. Segundo os PCNs, o ensino de função deveria ser introduzido espontaneamente a partir de situações contextualizadas, com exposições algébricas e gráficas descrevendo situações de variação e dependência entre duas grandezas, ao invés da forma tradicional que, normalmente hoje em dia, os professores ensinam estabelecendo como pré-requisito o estudo de números e conjuntos. Portanto, pode-se inferir que é necessário que o professor conheça os métodos de transposição didática do conceito de função, para que seja capaz de oferecer aos seus alunos um ambiente de diálogo e reflexão que lhes permita criar uma concepção espontânea de variação e de associação entre duas grandezas. 
Enfatizamos a necessidade de se conhecer a construção do conceito de função historicamente, bem como de se saber como se dá a transposição didática deste conceito nos vários mecanismos onde ela ocorre, para que se possa ter clareza do caminho a seguir numa sala de aula do Ensino Médio. Concluímos com este estudo preliminar que as definições formais e a introdução de função como relação entre conjuntos numéricos não são o melhor caminho para uma construção significativa deste conceito. Sugere-se um trabalho via resolução de problemas que permita ao aluno modelar situações e as contextualizar, dando ênfase às diversas representações de proporcionalidades, variabilidades, pois desta forma teremos elementos fundamentais para a formalização com possibilidade de uma aprendizagem mais significativa do conceito de função, proporcionando aos alunos a apropriação das noções de dependência, correspondência, variáveis dependentes e independentes, além de utilização crítica deste conceito.

\section{REFERÊNCIAS}

BRASIL, SEMTEC. PCN + Ensino Médio: Orientações Educacionais complementares aos Parâmetros Curriculares Nacionais. Ciências da natureza, matemática e suas tecnologias. Brasília: MEC, SEMTEC, 2002.

BOYER, Carl, B. História da Matemática. Tradução GOMIDE, E. F. 7̣ Ed. São Paulo: Edgard Bluger, 1974.

DOMINGUINI, L. A transposição didática como intermediadora entre o conhecimento científico e o conhecimento escolar. Revista Eletrônica de Ciências da Educação, Campo Largo, v. 7, n. 2, p. 1-16, nov. 2008. Disponível em < http://revistas.facecla.com.br/index. php/reped/article/view/472> Acesso em $16 / 07 / 2012$.

LEITE, M. S. Contribuições de Basil Bernstein e Yves Chevallard para a discussão do conhecimento escolar. Dissertação de mestrado apresentada ao Programa de PósGraduação em Educação. PUC-Rio. 2004. Disponível em $<$ http://www.maxwell.lambda.ele.puc-rio.br/ Busca etds.php?strSecao=resultado\&nrSeq=5269 @1> Acesso em 18/07/2012. 
MARANDINO, M. Transposição ou recontextualização? Sobre a produção de saberes na educação em museus de ciências, em: Revista Brasileira de Educação, São Paulo, n. 26, p. 95-108, mai./ago. 2004.

OLIVEIRA, N. Conceito de função: uma abordagem do processo ensinoaprendizagem. 1997. 174 f. Dissertação de Mestrado em Ensino da Matemática. PUC São Paulo. 1997.

PONTE, J. P. 0 conceito de função no currículo de Matemática. Revista Educação e Matemática, APM, Portugal, n.15, p. 3-9, 1990. 